\title{
A formação acadêmica em terapia ocupacional e as concepções sobre o processo saúde-doença
}

\author{
Academic development in occupational \\ therapy and its concepts about health-sickness process \\ Teresa Cristina Brito Ruas ${ }^{1}$ Fernanda Castilho Leite ${ }^{1}$, Marco Akerman ${ }^{1,2}$, Heloisa Ravanini Gagliardo ${ }^{3}$ \\ ${ }^{1}$ Faculdade de Medicina do ABC (FMABC) - Santo André (SP), Brasil. \\ ${ }^{2}$ Faculdade de Saúde Pública, Universidade de São Paulo (USP) - São Paulo (SP), Brasil. \\ ${ }^{3}$ Universidade Estadual de Campinas (UNICAMP) - Campinas (SP), Brasil.
}

DOI: http://dx.doi.org/10.7322/abcshs.v40i3.798

\section{RESUMO}

Introdução: Diante de uma cultura biológica e organicista, as concepções sobre saúde e doença dialogadas no ensino superior, ainda, são influenciadas pela lógica sintomática e medicalizante. Objetivo: Diante desse contexto, os objetivos deste estudo foram o de analisar tais concepções em uma experiência de ensino-aprendizagem do curso de terapia ocupacional da Faculdade de Medicina do ABC, em Santo André. Métodos: Como princípio metodológico central, optou-se pela experiência do aluno, enfocando-o como sujeito ativo de reflexões/narrativas diante da prática supervisionada. As narrativas foram coletadas por meio de diários de campo individuais e categorizadas em unidades temáticas. Resultados: Percebeu-se, majoritariamente, que o processo saúde-doença foi compreendido como polar, um se contrapondo ao outro. Enquanto a saúde foi a expressão de bem-estar completo/equilíbrio, a doença foi o oposto. Poucos estudantes consideraram a categoria das necessidades sociais em saúde na determinação do processo saúde-doença na infância. Conclusão: Conclui-se que essa experiência proporcionou aos alunos a compreensão de que, para o enfrentamento das necessidades em saúde infantil no Capuava, é necessário analisar saúde e doença, primeiramente, como processos vividos, sentidos e contextualizados com a própria história, cultura, subjetividade e inter-relacionados com os determinantes/necessidades sociais apresentados pelas crianças, sua família e o entorno.

Palavras-chave: educação superior; recursos humanos em saúde; terapia ocupacional.

\section{ABSTRACT}

Introduction: Before a biologic and organicist culture, conceptions about health and illness discussed in the superior education are still influenced by the symptomatic and medicating logic. Objective: Considering this context, the objectives of this study are aimed at analyzing such conceptions in a teaching-learning experience of the occupational therapy course in the Faculdade de Medicina do ABC in Santo André city. Methods: As a central methodologic principle, we have opted by the experience acquired by the student, focusing him/her as the active subject of reflections/narratives before the supervised practice. Narratives have been collected from individual field diaries and categorized into thematic units. Results: It has been principally perceived that the health-illness process was understood as being polar, with one of them in opposition to the other one. While health is the expression of complete wellbeing/equilibrium, illness means the lack of it. Few students have taken into consideration the category of social necessities in health terms in determining the health-illness process in childhood. Conclusion: We have concluded that this experience provided the students with the understanding that to face the childhood health necessities in Capuava, it is necessary that health and illness be primarily analyzed as processes experienced, felt, and contextualized with its own history, culture and subjectivity, and interrelated with socia determinants/necessities presented by the children, their families, and the environment.

Keywords: education, higher; health manpower; occupational therapy.

Recebido em: 14/07/2015

Revisado em: 10/09/2015

Aprovado em: 04/10/2015

Autor para correspondência: Fernanda Castilho Leite - Avenida Príncipe de Gales, 821 - Príncipe de Gales - CEP: 09060-650 - Santo André (SP), Brasil E-mail: fernanda.leite@fmabc.br

Conflito de interesses: nada a declarar. 


\section{INTRODUÇÃO}

A sociedade ocidental passa por mudanças, características de um período de transformação e instabilidades sociais ${ }^{1-3}$. Nesse contexto, as instituições de ensino superior estão diante do valioso e universal desafio de como educar e de como relacionar as práticas pedagógicas às realidades e necessidades atuais e sociais ${ }^{3-6}$.

Verifica-se que as práticas pedagógicas na saúde ainda privilegiam a visão organicista e medicalizada das diferenças individuais, que nos acompanha desde os movimentos de eugenia e de saúde pública que ocorreram no início do século XX. Constituem-se práticas homogêneas e excludentes que não privilegiam os significados, a cultura e o ponto de vista dos grupos sociais, fundamentando-se em um discurso normativo, capaz de vigiar, de examinar, de definir sanções, de corrigir e de classificar todo e qualquer desvio do que é considerado "normal" e "aceito socialmente"2,4-9.

No ensino superior, o setor da saúde tem um discurso pedagógico muito normatizador sobre a relação de poder e saber diante do processo saúde-doença. Essa relação ainda é transmitida com base em um saber positivista, organicista e biologizante, o qual valida e trata a saúde como a ausência de doença, incapacidade e/ou deficiência intrínseca e centrada no próprio indivíduo. O olhar clínico sobre essa relação entre saúde e doença objetiva ver, no ser humano, o produto de seu corpo, negando a possibilidade de fazer dele e de sua saúde um produto de suas técnicas, modos de vida e representações sociais ${ }^{9-11}$.

Toda essa forma de compreender o corpo e seus estados é fruto histórico e temporal. A história da sociedade ocidental demonstra que sempre houve a necessidade de justificativas de alguma ordem, com seus respectivos critérios, que possibilitassem identificar e segregar as pessoas que perturbassem a ordem estabelecida, seja por questionarem as ordens vigentes, seja por não apresentarem padrões iguais de comportamento ${ }^{6,7,9}$.

No entanto, a compreensão das práticas pedagógicas na saúde não pode utilizar a bagagem histórica excludente como obstáculo, mas sim como princípio de direcionamento de outras ações educativas, de forma que estas alcancem as necessidades e os direitos sociais/culturais de qualquer indivíduo e de qualquer comunidade $e^{4,5,12}$.

A ação em saúde mobiliza repertórios teóricos e práticos, sendo o último reflexo do primeiro. Portanto, é fundamental para o profissional da saúde valorizar a importância dos contextos político, social, econômico e até afetivo do espaço onde atua.

Dessa forma, o desafio da educação na graduação dos profissionais de saúde é instigar a curiosidade e a capacidade de reflexão e de crítica do aluno, tornando-o capaz de relacionar as competências teóricas com as trazidas por sua própria história de vida, inter-relacionadas com as demandas e necessidades atuais de toda a sociedade ${ }^{13}$.

O objetivo deste estudo foi analisar/identificar no discurso científico, nas narrativas e na prática supervisionada de alunos do quarto ano de terapia ocupacional da Faculdade de Medicina do $\mathrm{ABC}$, as concepções sobre o processo saúde-doença.

\section{MÉTODOS}

Este estudo teve como princípio metodológico central a própria experiência do aluno. Foi desenvolvido no estágio supervisionado sobre infância, na unidade básica na comunidade do Capuava em Santo André, elaborado sob as Diretrizes e Normas Regulamentadoras de Pesquisas Envolvendo Seres Humanos, de acordo com a Resolução n ${ }^{\circ}$ 466/12 (CNS) e aprovado pelo Comitê de Ética e Pesquisa da Faculdade de Medicina do ABC, com o protocolo de número 01083112.6.0000.0082.

O diálogo entre narrativa e reflexões pessoais e profissionais contribui para que evitemos a afirmação "o sistema social conscientemente envolve as pessoas numa espiral de ação sem reflexão"14 e contribui também para que os alunos percebam que "a reflexão sobre determinada ação é uma estratégia”, pontuando que a estratégia não, necessariamente, designa um programa predeterminado que basta ser aplicado em um determinado espaço e tempo ${ }^{6}$. Pelo contrário, a estratégia permite, a partir de uma decisão inicial e pessoal, prever certo número de cenários para a ação. Uma ação que pode ser dotada de sentido para redefinir significados e produzir novas e outras estratégias ${ }^{6,14-16}$.

Esse processo didático de reflexão ocorria uma vez por semana, com duração de 60 minutos, após o término das atividades propostas no estágio. O estágio obrigatório na área do desenvolvimento infantil ocorre semestralmente, uma vez por semana, com duração de cinco horas, e tem como objetivo o aprendizado de ações terapêutico ocupacionais de promoção da saúde infantil ancoradas na realidade social da comunidade do Capuava, com interface com os princípios da universalidade, da integralidade e da equidade.

O estágio iniciou-se em agosto de 2010 e, até o momento da coleta de dados da presente pesquisa, tivemos cinco grupos de alunos (cinco semestres), com um total de 25 alunos do quarto ano de terapia ocupacional. Cada aluno foi identificado com a letra $\mathrm{P}$ (participante), seguida por seu respectivo número, o qual foi definido de acordo com a sequência das turmas - em cada turma, seguiu-se a ordem alfabética. Os participantes receberam e assinaram o Termo de Consentimento Livre e Esclarecido.

As reflexões e as ações desenvolvidas pelos alunos eram anotadas em um diário de campo e discutidas em grupo, semanalmente, com a professora responsável, no mesmo momento destinado às reflexões individuais/grupais que ocorriam após o término das atividades do estágio, como pontuado acima. Os diários foram entregues à educadora responsável, ao fim de cada mês, durante os cinco meses de estágio de cada grupo de alunos, até o fim deste estudo. Esses diários foram lidos e entregues para os alunos, permanecendo uma cópia com a professora.

A categorização das narrativas foi temática e de acordo com os princípios de Bardin ${ }^{17}$. Foram transcritas pela pesquisadora responsável e organizadas, em unidades temáticas, de acordo com os principais objetivos deste estudo, procurando congregar as unidades de significação compreendidas na leitura e análise das narrativas. 
A forma escolhida para incluir e/ou excluir as narrativas e seus trechos representativos veio a partir do próprio desenvolvimento conceitual, reflexivo e crítico que os alunos expressavam ao longo do estágio. Como educadora, observei, principalmente nos dois primeiros meses de estágio, que as narrativas entregues e as discussões ocorridas após o término das atividades propostas eram descritivas. Os alunos descreviam os métodos utilizados e as ações realizadas sem, frequentemente, a presença da reflexão de como aquele método ou aquela ação impactava a própria concepção que trazia sobre saúde e doença, diante do processo de formação em terapia ocupacional.

Por outro lado, diante das experiências práticas, da leitura e do estudo de textos de apoio entregues ao longo das supervisões e do amadurecimento conceitual e pessoal adquiridos pela maioria dos alunos, a partir do terceiro mês de estágio, as narrativas começaram a demonstrar traços reflexivos, críticos, questionadores sobre os conceitos de saúde e doença em uma unidade básica de saúde, objetivando a lógica da promoção da saúde infantil. Portanto, optou-se por incluir narrativas com trechos reflexivos, críticos e questionadores e excluir aquelas com trechos puramente descritivos.

\section{RESULTADOS E DISCUSSÃO}

Diante da análise das narrativas, foram elaboradas duas grandes categorias temáticas, expostas logo abaixo: "Saúde e suas diferentes concepções" e "Doença: um estado de desequilíbrio", cada uma com as suas respectivas subcategorias.

\section{Categoria temática 1: \\ Saúde e suas diferentes concepções}

Nesta categoria temática, foram elaboradas quatro subcategorias: "Saúde como um estado de equilíbrio e harmonia", "Saúde como um estado de harmonia e seus determinantes sociais" "Saúde como bem-estar e qualidade de vida" e "Saúde e os valores pessoais".

Abaixo estão todas as quatro subcategorias, seguidas de uma explanação mais específica, e, diante da semelhança de conceitos, optou-se por uma única discussão, relatada após a quarta subcategoria.

\section{Subcategoria temática 1: Saúde como um estado de equilíbrio e harmonia}

Saúde não é apenas a ausência de doença, mas um estado de equilíbrio, de bem-estar e de harmonia entre os aspectos físico, mental e social. (P4, P5, P11, P13, P14, P15, P16, P17, P21, P22, P23)

\section{Subcategoria temática 2: Saúde como um estado de harmonia e seus determinantes sociais}

Entende-se por saúde o perfeito bem-estar físico, mental e social dos indivíduos, além do direito a moradia, saneamento básico, alimentação, trabalho, entre diversos outros fatores/determinantes sociais que, sendo ausentes, propiciam para que o processo não saudável aconteça, fazendo com que a saúde não seja apenas a ausência de doenças, no aspecto biológico. (P1, P2, P9, P10, P12, P18)

\section{Subcategoria temática 3: Saúde como bem-estar e qualidade de vida}

Saúde é sentir-se bem num contexto mental, físico e também social. Creio que não seja somente a ausência de doenças, porém um conjunto de fatores que nos culmine em bem-estar e que proporcione qualidade de vida. (P8)

\section{Subcategoria temática 4: Saúde e os valores pessoais}

[...] saúde é ter força para lutar por aquilo que deseja e acredita... é também ser feliz, fraterno, honesto...

Apesar de a grande maioria dos estudantes relatar a inter-relação entre os aspectos físico, mental e social na determinação do processo de saúde e, portanto, não observar apenas a parte biológica como a única razão científica para tal, conforme a própria Organização Mundial de Saúde (OMS) defende, ainda verifica-se, em ordem de importância, a primazia do aspecto biológico sobre os outros fatores, tais como o mental e/ou o social.

Mesmo que apareça o aspecto afetivo, cognitivo e/ou social nos relatos, há uma hierarquia entre as diferentes partes que contemplam "o corpo humano". O aspecto biológico ainda aparece como "carro-chefe", como se, na ausência de sua primazia, as outras partes "sofressem" consequências. Foi percebido, majoritariamente, um pensamento claro e organizado na concepção de um corpo mecânico, composto por órgãos e funções que determinam a sua normalidade e a sua funcionalidade $\mathrm{e}^{7,9,11,18,19}$

Foram relatados fatores multicausais sobre o processo de saúde, tais como a qualidade de vida, o bem-estar, a necessidade de moradia, alimentação e lazer adequado, etc. Porém, todos esses aspectos que poderiam ter interface e influência maior perante o conceito de cultura, de determinantes sociais, de sociedade, de trabalho, de cidadania e, portanto, diante das bases teóricas que guiam a saúde coletiva, não foram relatados de maneira objetiva, contextualizada e/ou mais clara. Percebeu-se uma nítida dificuldade no intercruzamento teórico e/ou prático das ciências biológicas com os conceitos das ciências sociais e humanas, a fim de se obter uma visão mais crítica e mais política do processo de saúde.

Da mesma forma que a ciência moderna segmenta o corpo e este passa a ser compreendido como um conjunto de "peças/partes", o que é afirmado diante da visão hierárquica que os alunos têm dos aspectos físico, mental, social que contemplam o corpo 
humano, aqui, a hierarquia, ou melhor, a compreensão de "pesos diferentes" entre o aspecto biológico e social também deveria ocorrer e ser relatada pelos alunos. Uma visão mais analítica sobre o processo de saúde, diante dos determinantes sociais e econômicos, poderia advir, se os futuros profissionais de saúde compreendessem que os fatores biológicos não apresentam o mesmo peso e a mesma importância diante dos fatores sociais/econômicos e vice-versa ${ }^{9,11,20-22}$.

Sabemos o quanto a alimentação, a moradia, o lazer, a educação e as práticas esportivas são importantes para a promoção da saúde e para a prevenção de doenças. No entanto, sabemos também de uma relação direta e determinante entre a dimensão do trabalho e a condição de consumo dos aspectos relatados acima. Ou seja, embora os alunos representem as dimensões econômica e social diante do relato do consumo de bens, ela ainda não aparece em um papel de comando na vida social do indivíduo ${ }^{22,23}$.

Quanto à frequente definição de saúde pela grande maioria dos participantes deste estudo, é válido ressaltar a definição de "bem-estar": "saúde não é apenas a ausência da doença, mas uma situação de perfeito bem estar físico, mental e social". O que seria, portanto, o entendimento real e "palpável" de "um completo bem-estar físico, mental e social"? Seria realmente uma realidade ou seria uma utopia, ou até mesmo uma fantasia? Sabe-se o quanto é importante demonstrar aos alunos da área da saúde e aos terapeutas ocupacionais os conceitos e as teorias elaborados e difundidos pela OMS. Sabe-se, também, o quanto é importante uma visão crítica, reflexiva e política diante dos conceitos e das visões que fundamentam a graduação na área da saúde.

A definição de saúde da OMS, inclusive avançada para a época em que foi estabelecida, é, no momento, irreal, ultrapassada e unilateral, sendo impossível caracterizar e/ou definir um estado humano de perfeição, até porque não é plausível verificar o "bem-estar" e/ou a "perfeição" sem que estejam inseridos em um contexto que lhes empreste sentido, a partir da linguagem e da experiência íntima de cada sujeito e de sua historicidade ${ }^{24}$.

Essa "negligência" demonstrada pela área da saúde, da experiência íntima/histórica de cada sujeito e de seus valores pessoais, e perante o olhar clínico, biológico e medicalizante - um olhar ainda organizador e estruturante da ciência moderna - , pode ser um dos fatores que explicam a carência de narrativas na quarta subcategoria. Esse resultado pode ser sim um indicativo de como é difícil compreender, por exemplo, que o processo da saúde é um atributo da vida. Uma vida cotidiana, individual e singular na qual cada indivíduo vivencia as multiplicidades de suas experiências e de seus sentidos, conforme ele esteja em sua casa, em seu trabalho, com amigos ou desconhecidos ${ }^{6}$.

Além disso, o pensamento de que a saúde pode ser "um bem" garantido diante do acesso a serviços/procedimentos/equipamentos médicos/hospitalares e a práticas saudáveis que favorecem a qualidade de vida, como alimentação adequada, exercícios físicos, entre outros, demonstra o quanto a influência histórica de como foram fundamentados os princípios da saúde pública no Brasil ainda rege uma forte e determinante influência na concepção e representação que formamos sobre o conceito de saúde $e^{21,22,25}$. Assim, a saúde ainda é vista como uma responsabilização do sujeito, sem, porém, a devida análise e contextualização social para a explicação dos problemas que podem surgir ao longo do existir humano.

Abaixo, segue a categoria 2 e suas subcategorias.

\section{Categoria temática 2: \\ Doença: um estado de desequilíbrio}

Nesta categoria, criaram-se três subcategorias nomeadas: "O desequilíbrio", "A ruptura no cotidiano e no bem-estar" e " Doença e o desempenho humano", nas quais observou-se, também, uma "certa" homogeneidade de concepção. As subcategorias 1 e 2 foram agrupadas em uma mesma discussão, diante da semelhança das representações. Logo após, encontram-se a última subcategoria e sua respectiva discussão.

\section{Subcategoria 1: 0 desequilíbrio}

"Doença é um desequilíbrio físico, mental ou social que afeta a saúde e a qualidade de vida do indivíduo." (P2, P3, P5, P9, P13, P15, P18, P20, P23)

\section{Subcategoria 2: A ruptura no cotidiano e no bem-estar}

"Doença é quando há uma ruptura no bem-estar do indivíduo, sendo esta ruptura no meio mental, no meio social ou no meio físico." (P14, P17, P21, P24)

"A doença é quando ocorre uma ruptura do cotidiano de uma pessoa, ruptura essa que atinge o indivíduo no social, na sua saúde mental, na sua saúde física." (P1, P4, P10, P16)

Nessas duas subcategorias, foi perceptível uma interligação entre os "fatores incapacitantes", o cotidiano, o meio social e o dia a dia do sujeito. Porém, a primazia da história individual, provinda de possíveis patologias e/ou de sintomas incapacitantes diante do processo histórico, cultural e social, ainda tem um peso muito grande na narrativa dos alunos.

Semelhante ao que foi encontrado na categoria sobre as representações de saúde, o aspecto cultural, social e histórico têm pesos e hierarquias muito semelhantes no processo do adoecimento. Portanto, não foram, também, observados relatos sobre as influências diretas que eles exercem em um contexto populacional e/ou comunitário, principalmente no que tange ao aspecto de qualidade de vida, cotidiano e meio social, justamente diante da determinação histórica e cultural do próprio impacto da natureza do trabalho na sociedade contemporânea sobre o sujeito e suas reais causas de adoecimento e/ou exclusão social ${ }^{6,9,21,22,24,26-28}$.

É válido afirmar que essa dificuldade em analisar criticamente as causas e os fatores que levam ao adoecimento não é uma característica somente desse grupo de alunos. Como eu mesma afirmei, atinge os futuros e os atuais profissionais. Carregamos em nossa bagagem conceitual: 
[...] o método anátomo-clínico representa a historicidade do próprio conhecimento sobre o ser doente, sobre o corpo doente, da medicina que se coloca positivamente e como tal é apreendida. Esse conhecimento só pode se constituir a partir do momento em que se descola da metafísica, de explicações sobre a essência das doenças; a partir do momento em que o olhar se desloca para a visibilidade da morte, a doença transforma-se, torna-se legível e plenamente enunciável, expondo-se à dissecção da linguagem e do olhar. O método anátomo-clínico resulta de uma estrutura em que se articulam o espaço, a linguagem e a morte. E ao ser capaz de olhar a morte, a medicina constrói, para si, um novo estatuto epistemológico ${ }^{9}$, Este é inserido e dirigido pelos sinais e sintomas.

Assim como a saúde foi definida como um "perfeito bem-estar", a doença foi relatada, majoritariamente, como um desequilíbrio/ ruptura. Aqui também é muito cabível a reflexão do que seria um desequilíbrio dos aspectos físico, mental e social. A definição de doença está ultrapassada, principalmente, porque causa uma separação entre o físico, o mental e o social. Será mesmo que existe uma clivagem entre esses aspectos e todos eles devem estar em equilíbrio ${ }^{24} \mathrm{~A}$ inexistência de uma clivagem entre mente e soma nem sempre é muito clara, com os dois aspectos supracitados. Os autores complementam dizendo que a continuidade entre o psíquico e o somático tem sido objeto de vários estudos: "Se o psíquico responde ao corporal e vice-versa, fala-se, então, de um sistema onde não se delineia uma nítida divisão entre ambos"24.

Podemos compreender, diante de toda a discussão acima, que essa divisão entre o corpo, a mente e o social é fruto de uma ciência cartesiana, a qual potencializa a dicotomia entre mente e corpo e minimiza e/ou anula os efeitos sociais, históricos e culturais no modo de viver, existir e adoecer.

Abaixo segue a última subcategoria e sua respectiva discussão.

\section{Subcategoria 3: Doença e o desempenho humano}

Doença é um desequilíbrio de ordem biológica, psíquica ou social, deflagrado por vários fatores que comprometem o cotidiano do indivíduo, interferindo no seu desempenho funcional. Porém, nem todos os fatores são incapacitantes, sendo possível resgatar a potência do sujeito para que ele expresse as suas possibilidades de ação e seja ativo socialmente. (P11)

Nesta subcategoria apareceu, com bastante frequência, a relação entre a doença e suas consequências diante do papel ativo e do desempenho funcional nas atividades diárias e produtivas de todo indivíduo. Sabemos, sim, que a condição de adoecimento pode interferir nas atividades cotidianas, principalmente na qualidade do fazer humano. Quando o terapeuta ocupacional focaliza o seu olhar na qualidade da ação, afirmamos o quanto é possível continuar a viver, mesmo que nossa existência seja marcada por dificuldades e/ou limitações de origens/causas diferentes.
Porém, a compreensão e a preocupação com a funcionalidade, com o máximo desempenho e com a garantia de que o indivíduo continue e seja ativo socialmente estão, majoritariamente, nas narrativas dos alunos e em nossas práticas, ligadas à condição econômica e à força do trabalho que regem os princípios de uma sociedade capitalista.

O terapeuta ocupacional ainda se preocupa muito com a normatização de corpos e comportamentos para que o sujeito possa ser incluído e aceito socialmente de acordo com as regras de sociedades marcadas pela competitividade, pelo lucro e pelo máximo desempenho. Em nosso olhar, ainda focalizamos o indivíduo biopsicossocial, com suas dificuldades/limitações/deficiências, como principal foco de atenção e intervenção terapêutica, sem questionarmos, frequentemente, a estrutura e as desigualdades sociais relacionadas ao processo de adoecimento ${ }^{10,20,21,29}$.

As concepções defendidas por teóricos de grande importância nos ajudam a entender a relação entre um corpo ativo e funcional e a expressão de um máximo e perfeito desempenho, como descrito na maioria das narrativas. Mesmo com pontos de vista diferentes, todos esses teóricos afirmam o quanto a ciência moderna prioriza e valoriza o corpo como "um maquinário" perfeito, que não pode ter falhas e deve ser normatizado/disciplinado diante das normas/ regras sociais e econômicas vigentes nas sociedades capitalistas/ ocidentais. A medicina e todos os seus conhecimentos e áreas, como as profissões de saúde, são vistos como meios poderosos para garantir a normatização e a perfeição do corpo e do comportamento, a fim de se garantir uma ordem social em contextos tão marcados pela desigualdade $e^{6,7,18,26,29-31}$.

Os estudantes participantes desta pesquisa demonstraram em suas narrativas o quanto a educação em saúde acumulou, historicamente, conteúdos, disciplinas e o aspecto pedagógico centrados na doença e na reabilitação clínica.

Verificou-se o quanto o processo saúde-doença foi compreendido como polar, um se contrapondo ao outro. Enquanto a saúde foi relatada, majoritariamente, como a expressão de bem-estar completo, de harmonia/equilíbrio, de hábitos saudáveis e de ser ativo no mundo, a doença foi relatada como o desequilíbrio, a falta da harmonia e da possibilidade de ser ativo e/ou ter um adequado desempenho funcional em suas atividades diárias/cotidianas. Além disso, poucos estudantes, apesar de uma grande maioria ter identificado a influência dos determinantes sociais no processo saúde-doença, consideraram, organizadamente, em suas reflexões, a categoria das necessidades sociais em saúde na determinação do processo saúde-doença na infância.

Assim, essas evidências ainda nos demonstram o quanto a formação e o conteúdo curricular dos cursos da área da saúde são, ainda, fragmentados e específicos, com poucos "espaços" teóricos e práticos que garantam o intercruzamento entre as ciências biológicas, humanas e sociais nas diversas áreas de conhecimento e competências que o campo da saúde necessita para a sua constituição. Afinal de contas, as concepções relatadas neste estudo indicam o quanto a saúde e a doença, ainda, precisam ser dialogadas, no ensino superior, como um processo natural e próprio do ser humano. 


\section{REFERÊNCIAS}

1. Damas LA. Conviver e aprender a estar no mundo: educação para a solidariedade. Mundo Saúde. 2002;26(3):393-406.

2. Galasso R. Informática na educação: perspectivas de inclusão. Mundo Saúde. 2002;26(3):389-92.

3. Giacon BDM. A educação necessária à inclusão. Mundo Saúde 2002;26(3):413-16. 4. Ferreira MCC. Formação de Professores. In: Mendes EG, Almeida MA, Willians LCA. Temas em Educação Especial: avanços recentes. São Carlos: Edufscar; 2004.

4. Freitas SN. Formação de Professores: interfaces entre a educação e a educação especial. In: Mendes EG, Almeida MA, Willians LCA. Temas em educação especial: avanços recentes. São Carlos: Edufscar; 2004

5. Morin E. Introdução ao pensamento complexo. Tradução Eliane Lisboa. 4 ed. Porto Alegre: Sulina; 2011.

6. Focault M. As palavras e as coisas. São Paulo: Martins; 1992

7. Silva TT. Descolonizar o currículo: estratégias para uma pedagogia crítica. In: Costa MV. Escola básica na virada do século: Cultura, política e currículo. São Paulo: Cortez; 1996. p. 61-72.

8. Moysés MAA. A institucionalização invisível: crianças que não aprendem na escola. Campinas: Mercado de Letras; 2008. p.256.

9. Barros DD, Lopes RE, Galheigo SM. Projeto metuia: terapia ocupacional no campo social. Mundo Saúde. 2002;26(3):365-9.

10. Minayo MCS. O desafio do conhecimento: pesquisa qualitativa em saúde. São Paulo: Hucitec; 2008.

11. Barros DD, Lopes RE, Galheigo SM. Novos espaços, novos sujeitos: a terapia ocupacional no trabalho territorial e comunitário In: Cavalcanti A, Galvão C. Terapia ocupacional: fundamentação e prática. Rio de Janeiro: Guanabara Koogan; 2007.

12. Merhy E. O capitalismo e a saúde pública. São Paulo: Papirus; 1985.

13. Bondia JL. Notas sobre a experiência e o saber da experiência Rev Bras Educ. 2002;(19):20-8. http://dx.doi.org/10.1590/S1413-24782002000100003

14. Heidegger M. Ser e tempo. Petropólis: Vozes; 2006.

15. Marcolino TQ, Mizuquami MGN. Narrativas, processos reflexivos e prática profissional: apontamentos para a pesquisa e formação. Interface. 2008;12(26):541-7.

http://dx.doi.org/10.1590/S1414-32832008000300007

16. Bardin L. Análise de conteúdo. Lisboa: Edições 70; 1977.
17. Focault M. Vigiar e punir. Petrópolis: Vozes; 1989.

18. Morin E. Educação e complexidade: os sete saberes e outros ensaios. In: Almeida MC, Carvalho EA. São Paulo: Cortez; 2000.

19. Galheigo SM. Da adaptação psico-social à construção do coletivo: a cidadania enquanto eixo. Versão ampliada e revisada da palestra apresentada ao III Congresso Brasileiro de Terapia Ocupacional. Curitiba: (10 a 15 de outubro); 1993.

20. Lopes RE. Cidadania, políticas públicas e terapia ocupacional. Tese (Doutorado) - Faculdade de Educação da Universidade Estadual de Campinas. Campinas: 1999.

21. Reis AM, Soares CB, Campos CMS. Processo saúde-doença: concepções do movimento estudantil da área da saúde. Saúde Soc. 2010;19(2):347-57.

http://dx.doi.org/10.1590/S0104-12902010000200011

22. Oliveira DC, Sá CP, Gomes AMT, Ramos RS, Pereira NA, Santos WCR. A política pública de saúde brasileira: representação e memória social de profissionais. Cad Saúde Pública. 2008;24(1):197-206.

http://dx.doi.org/10.1590/S0102-311X2008000100020

23. Segre M, Ferraz FC. O conceito de saúde. Rev Saúde Pública. 1997;31(5):538-42

http://dx.doi.org/10.1590/S0034-89101997000600016

24. Nunes ED. Saúde Coletiva: uma história recente de um passado remoto. In: Campos GWS, Minayo MCS, Akerman M, Drumond M, Carvalho YM. Tratado de Saúde Coletiva. São Paulo: Hucitec; 2006. p.19-39.

25. Déjour SCA. loucura do trabalho. São Paulo: Cortez; 1980.

26. Soares LBT. Terapia ocupacional: lógica do capital ou do trabalho? São Paulo: Hucitec; 1991.

27. Rocha EF. A terapia ocupacional e as ações na educação: aprofundando interfaces. Rev Ter Ocup Univ São Paulo. 2007;18(3):122-7.

http://dx.doi.org/10.11606/issn.2238-6149.v18i3p122-127

28. Castel R. As metamorfoses da questão social. Petrópolis: Vozes; 1998.

29. Castel R. Da indigência à exclusão, a desfiliação. Precariedade do trabalho e vulnerabilidade relacional. In: Lancetti A. Saúde e loucura. São Paulo: Hucitec; 1994. p. 21-48.

30. Castel R. As transformações da questão social. In: Belfiore WM, Bógus L, Yasbek MC. Desigualdade e a questão social. São Paulo: EDUC; 1997. p. 161-90. 